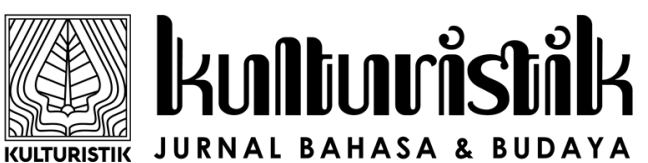

Vol. 2, No. 1, Januari 2018, 9-18

Available Online at https://ejournal.warmadewa.ac.id/index.php/kulturistik DOI: dx.doi.org/10.22225/kulturistik.2.1.442

\title{
BENTUK-BENTUK TINDAKAN BELANDA TERHADAP PEJUANG PADA MASA REVOLUSI FISIK DI BALI
}

\author{
Ida Bagus Astika Pidada \\ Universitas Warmadewa \\ astikapidada@gmail.com
}

\begin{abstract}
ABSTRAK
Artikel ini bertujuan untuk mengungkap kejadian tentang bentuk-bentuk tindakan Belanda terhadap para pejuang pada masa revolusi pisik di Bali. Penelitian ini tergolong penelitian kualitatif. Pengumpulan dilakukan dengan teknik dokumentasi dan wawancara. Data yang berhasil dikumpulkan diolah dan diorganisasi untuk dilakukan penafsiran-penafsiran atau interpretasi terhadap data. Berdasarkan penelitian yang dilakukan dapat disimpulkan bahwa revolusi fisik yang terjadi di Bali dari tahun 1945 - 1950 cukup lama dapat dipertahankan oleh para pejuang dalam menghadapi Belanda. Hal ini disebabkan karena pejuang dengan rakyat pada waktu itu bersatu. Berbagai macam taktik atau strategi dilakukan oleh para pejuang sehingga Belanda sangat sulit untuk mengalahkannya. Dalam menghadapi para pejuang di Bali selain menggunakan kekuatan militer, Belanda juga menggunakan tindakan lain untuk mempengaruhi rakyat seperti: membagikan jajan, rokok, uang logam, kain batik, dan nasi. Tindakan yang dilakukan oleh Belanda kepada rakyat baik secara langsung maupun tidak langsung melalui mata - matanya. Tujuan melakukan tindakan ini agar rakyat bersimpati kepada Belanda.
\end{abstract}

Kata kunci: tindakan, Belanda, pejuang, revolusi fisik

\begin{abstract}
[Title: The Forms of Dutch Action to the Soldiers at the Physical Revolution in Bali] This article aims to reveal events about the forms of Dutch action against the soldiers during the period of the physical revolution in Bali. This research is qualitative research. The collection is done by documentation and interview techniques. The data collected is processed and organized for interpretation of the data. Based on research conducted it can be concluded that the physical revolution that occurred in Bali from 1945 - 1950 long enough to be maintained by the soldiers against the Netherlands. This is because the soldier with the people at that time united. Various tactics or strategies were carried out by the soldiers so the Dutch were very difficult to defeat them. In addition to using military force, the Butch also uses other actions to influence people such as: distributing snacks, cigarettes, coins, batik cloth, and rice. The actions taken by the Dutch to the people either directly or indirectly through his spies. The purpose of doing this is for the people to sympathize with the Dutch.
\end{abstract}

Keywords: act, Netherlands, soldiers, physical revolution

\section{PENDAHULUAN}

Proklamasi Kemerdekaan Indonesia diproklamirkan atas nama bangsa Indonesia oleh IR.Sukarno yang didampingi DRS. Mohammad Hatta pada tanggal 17 Agustus 1945 di Jalan Pegangsaan Timur No.56 Jakarta pada pukul 10.00 WIB (Kartodirdjo \& dkk., 1977: 29). Berita proklamasi tidak begitu saja langsung didengar di daerah - daerah. Berita proklamasi kemerdekaan Indonesia baru 
diketahui di pulau Bali pada tanggal 23 Agustus 1945 setelah Mr. I Gusti Ketut Puja wakil Sunda Kecil duduk dalam panitia persiapan kemerdekaan Indonesia kembali dari Jakarta. Presiden Sukarno telah mengangkat beliau sebagai gubernur untuk wilayah Sunda Kecil. Di samping itu beliau juga membawa mandat presiden kepada Ida Bagus Putra Manuaba sebagai Ketua Komite Nasional Indonesia (KNI) untuk daerah Sunda Kacil. Pada waktu itu kota Singaraja ditetapkan sebagai ibu kota provinsi Sunda Kecil (A. Giri, 1984: 5) cf (Jarahdam XVI Udayana, 1974: 11). Berita proklamasi terlambat sampai di Bali disebabkan kurang lancarnya transportasi serta komunikasi antara pulau Bali dengan pulau Jawa. Suasana di Bali ketika itu Jepang masih menunjukkan sikap menjajah. Penjajahan Jepang sebenarnya sudah menyerah kepada sekutu meskipun demikian masih berusaha mempertahankan kekuasaannya.Kesempatan ini dimanfaatkan oleh para pejuang di pulau Bali untuk melakukan serangan umum kepada tangsi - tangsi Jepang di seluruh Bali. Serangan umum ini dilakukan pada tanggal 13 Desember 1945 pada malam hari. Setiap tangsi yang dihuni tentara Jepang harus diserbu sesuai dengan waktu dan tanggal yang ditetapkan. Serangan umum ini dipimpin oleh TKR di daerahnya masing - masing. Sebelum serangan dilakukan pada jam 13.00 kurang sedikit, tentara Jepang terlebih dahulu menembakkan senjatanya dengan hebat. Walaupun demikian ada kentongan beberapa yang dibunyikan sesuai dengan rencana. Tembakan senjata Jepang yang hebat membuat serangan umum yang telah ditetapkan menemui kegagalan. Tujuan diadakan serangan umum tersebut tidak lain adalah untuk memperoleh senjata. Kira - kira tiga (3) hari setelah serangan umum para pejuang yaitu Widjakusuma, Cokorda Ngurah, Wisnu, Wayan Ledang, I Gusti Wayan Debes, serta I Gusti Ngurah Rai berkumpul di Munsiang dekat Carangsari (Badung Utara). Adapun maksud pertemuan mereka adalah untuk mendiskusikan sebab - sebab kegagalan serangan umum serta mencari jalan keluar untuk mengatasinya. Dalam diskusi ini mereka menyimpulkan bahwa kita tidak mungkin memperoleh senjata dari Jepang di pulau Bali, oleh sebab itu mereka memutuskan untuk minta bantuan kepada Markas Besar Tentara Keamanan Rakyat (MBTKR) di Yogyakarta.

Pada tanggal 19 Desember 1945 I Gusti Ngurah Rai berangkat ke Jawa bersama - sama Wayan Ledang, Putu Wisnu, dan Cokorda Ngurah melalui Munsiang. Dalam perjalanan ini rombongan banyak menemui rintangan tetapi semua dapat diatasi dan mendarat di Wongsorejo yaitu kira - kira $20 \mathrm{~km}$ di sebelah utara Banyuwangi (Hardjawiganda \& dkk., 1982: 44).

Selanjutnya rombongan militer Belanda yang pertama mulai mendarat di pulau Bali bernama Brigade Y. Brigade Y didaratkan sepanjang pantai Sanur pada tanggal 2 Maret 1946. Rombongan militer Belanda ini lebih dikenal dengan nama "Gajah Merah ". Gajah Merah pada waktu ini didaratkan di Bali dan Lombok. Di Bali Gajah Merah yang ditugaskan batalyon 10 dan 11 di bawah komando Letkol Ter Meulen dan Letkol Pieter Camp. Setelah mendarat mereka langsung menduduki (1) Denpasar tanggal 2 Maret 1946, (2) tanggal 3 Maret 1946 di Gianyar, (3) tanggal 5 Maret 1946 di daerah Singaraja, (4) tanggal 7 Maret 1946 di Tabanan, Klungkung, Bangli, dan Karangasem, dan (5) terakhir di daerah Negara tanggal 13 Maret 1946. Dalam hal ini pulau Bali oleh Belanda dibagi atas 3 komando daerah militer yaitu Gianyar dan Denpasar dipegang oleh Kapten Cassa. Kemudian Letnan Groet memegang wilayah Klungkung, Bangli dan Karangasem. Sedangkan Kapten Ter Wilde memegang wilayah Tabanan, Negara dan Singaraja (Hardjawiganda \& dkk., 1982: 48 - 49). Datangnya pasukan Gajah 
Merah ke pulau Bali, situasi menjadi tidak tenang dan semakin genting. Oleh sebab itu Belanda kembali menarik pasukan Gajah Merah yang ada di Lombok sebanyak 3 kompi ke Bali.

Pada tanggal 3 April 1945 sekitar pukul 20.00 malam atas bantuan pasukan ALRI Banyuwangi, I Gusti Ngurah Rai dan kawan - kawan berangkat menuju Bali dan Muncar. I Gusti ngurah Rai berada di Jawa kurang lebih 3 (tiga) bulan. Kira - kira pukul 03.00 pagi dari arah timur muncul 2 (dua) buah motor bot Belanda. Mengetahui dalam perahu yang lewat adalah pejuang, tanpa komentar Belanda melancarkan tembakan. Ketika pristiwa ini terjadi gugur yaitu Cokorda Rai Gambir dan Cokorda Dharma Putra sedangkan tukang perahunya ditangkap oleh Belanda. Pada waktu ini I Gusti Ngurah Rai berada di belakang sekitar 1 (satu) kilometer. Adanya suara tembakan tersebut I Gusti Ngurah Rai mengambil keputusan untuk kembali lagi ke Muncar. Perjalanan dilanjutkan kembali oleh I Gusti Ngurah Rai dan kawan - kawan tanggal 4 April 1946 pukul 24.00 malam. Dengan 3 (tiga) buah perahunya I Gusti Ngurah Rai mendarat di daerah Yeh Kuning, sedangkan sisanya mendarat di daerah Pulukan. Salah seorang diantaranya yang mendarat di daerah Pulukan adalah Cokorda Ngurah (Pendit, 1979: 157). I Gusti Ngurah Rai selanjutnya memutuskan meninggalkan daerah ini untuk menuju desa Munduk Malang daerah Tabanan sesuai dengan rencana sebelumnya. Sebelum mendarat telah datang beberapa truk Belanda, berhubung para pejuang yang ditunggu tidak kunjung datang, akhirnya pasukan Belanda bergerak lagi kearah barat.

Di desa Munduk Malang daerah Tabanan pada tanggal 14 April 1946 berkumpullah para tokoh pejuang. Pertemuan ini yaitu membahas keadaan perjuangan di Bali juga keadaan di Yogyakarta. Pada waktu ini di desa Munduk Malang dibentuk MBODPRISK (Markas Besar Umum Dewan Perjuangan Rakyat Indonesia Sunda Kecil). Adapun pimpinannya yaitu Letnan Kolonel I Gusti Ngurah Rai sedangkan Made Wijakusuma dipilih sebagai wakilnya. Tindakan selanjutnya adalah membentuk markas - markas DPRISK tingkat kabupaten, yang nantinya merupakan tenaga penggerak di tempatnya masing - masing (Jajasan Kebaktian Proklamasi Daerah Propinsi Bali, 1968: 4).

Semenjak MBODPRISK berkedudukan di Munduk Malang maka rakyat Tabanan seperti desa Gadungan, Apit Yeh, Kemetug, Rijasa, Sawah, Dalang, Gempinis, Banjar Anyar, Sangketan serta yang lainnya, semangat rakyat makin meluap menuntut kepada para pejuang agar segera mengadakan perlawanan terhadap Belanda (Pindha, n.d.). Selanjutnya para pejuang dari desa Munduk Malang segera mengadakan serangan pos Belanda di desa Penebel serta mengadakan pencegatan iring - iringan Belanda di desa Pucuk kecamatan Selemadeg Tabanan. Dengan demikian dalam waktu relatif singkat Belanda mengetahui kedudukan para pejuang di desa Munduk Malang melalui kaki tangannya. Terjadilah kontak senjata antara pejuang melawan Belanda di desa Munduk Malang. Melihat kondisi daerah kurang aman maka Markas Besar Umum (MBO) dipindahkan ke desa Bengkel Anyar. Peristiwa ini terjadi tanggal 1 Juni 1946. Desa Bengkel Anyar terletak di sebelah timur laut desa Munduk Malang yaitu kurang lebih 7 km (Pendit, 1979: 180).

Melihat situasi pulau Bali yang dirasakan makin sulit serta adanya utusan yang datang dari para pejuang dari masing - masing daerah maka untuk menambah semangat rakyat diputuskan mengadakan perjalanan panjang dari barat ke timur. Perjalanan panjang ini dikenal dengan nama "Perjalanan Juni - Juli" atau 
“Long March"(Pendit, 1979:189). Perjalanan panjang atau long march dimulai tanggal 28 Mei 1946 dari desa Bengkel Anyar dengan mendaki Gunung Batukaru menuju daerah Buleleng. Selama perjalanan menuju kedaerah timur terjadi kontak senjata antara pejuang dengan Belanda. Dalam menghadapi para pejuang di Bali Belanda menggunakan berbagai macam tindakan untuk merebut hati rakyat serta membuat rakyat jera sehingga tidak bersedia membantu para pejuang.

Belanda melakukan berbagai tindakan kekerasan terhadap pejuang. Masalah yang penting untuk dikaji adalah bagaimanakah bentuk-bentuk tindakan yang dilakukan Belanda terhadap para pejuang pada masa revolusi pisik. Hal ini penting ditelaah untuk memahami bentuk-bentuk strategi yang diterapkan Belanda terhadap para pejuang sehingga muncul adanya kesadaran masyarakat akan arti penting pengorbanan para pejuang.

\section{METODE PENELITIAN}

Penelitian ini tergolong penelitian kualitatif yang berupaya mendeskripsikan bentuk-bentuk tindakan yang dilakukan oleh Belanda terhadap para pejuang dalam rangka menjajah kembali di Indonesia. Oleh karena itu, penelitian difokuskan pada masa/periode revolusi pisik tahun 1945-1950.

Pengumpulan dilakukan dengan teknik dokumentasi dan wawancara. Teknik dokumentasi adalah penelururan dokumen sejarah yang dipandang relevan. Heuristic terhadap tulisan yang tergolong dokumen sejarah dinilai berdasarkan kritik sumber. Wawancara mendalam untuk menggali informasi tentang perjuangan yang dilakukan oleh tokoh-tokoh yang mengalami atau ikut berjuang dalam revolusi pisik di Bali. Data yang berhasil dikumpulkan diolah dan diorganisasi untuk dilakukan penafsiran-penafsiran atau interpretasi terhadap data.

\section{PEMBAHASAN}

Berdasarkan informasi yang diberika oleh para informan dan dokumentasi sejarah terdapat berbagai bentuk tindakan yang diterapkan Belanda kepada pejuang pada masa revolusi pisik. Trik-trik yang ditempuh dalam rangka memenangkan pertempuran ada yang bersifat lunak dengan memberikan janji-janji manis, namun ada pula yang bersifat keras dengan melakukan intimidasi dan kekerasan pisik lainnya. Bentuk-bentuk yang pernah diterapkan Belanda terhadap pejuang dapat diuraikan sebagai berikut.

Pada waktu terjadinya Puputan Margarana, desa Marga diteror oleh Belanda. Penduduk diperintahkan kumpul di pasar. Tua muda, laki perempuan dan bahkan anak - anak. Mereka disiksa seperti dipukul, ditendang dan beberapa orang ditembak. Belanda sangat marah pada waktu ini. Tidak seorangpun rakyat yang membuka mulut atau menceriterakan dimana para pejuang berada. Disini rakyat sadar akan arti perjuangan kemerdekaan. Mereka tidak seorang pun mau berkhianat (Suralaga, 1982: IV).

Pada tanggal 16 Juli 1946 pagi - pagi benar ada pengumuman supaya semua bersedia mengambil makanan karena nasi sudah dating. Pada waktu itu para pejuang berada di desa Blandingan. Selanjutnya semua mengambil tempurung tempat nasinya menuju ketempat orang membagi - bagikan nasi. I Gusti Ngurah Pindha orang yang paling dulu sampai ditempat pembagian nasi itu. Yang membagikan nasi tersebut adalah langsung orang kampung dimana nasinya hanya satu besek cukup kira - kira untuk 20 orang. Ada hal yang mencurigakan yakni gerak - gerik orang yang membagikan nasi itu kelihatan gelisah dan mengulur - ulur waktu. 
Vol. 2, No. 1, Januari 2018, 13

Available Online at https://ejournal.warmadewa.ac.id/index.php/kulturistik DOI: dx.doi.org/10.22225/kulturistik.2.1.442

Beberapa kali nasi diaduk aduk dan dibawanya kesana kemari tetapi akhirnya dibagikan juga. Dua sampai tiga orang sudah mendapatkan nasi masing - masing dua sendok. Kira - kira 8 orang sudah mendapatkan pembagian nasi sedangkan I Gusti Ngurah Pindha dan 3 orang lagi masih menunggu. Terdengarlah suara kapal udara menderu - deru dari jurusan timur yang makin lama makin mendekat kemudian langsung menukik melepaskan tembakan 12,7. Para pejuang lari mencari perlindungan masing - masing. Sementara itu I Gusti Ngurah Pindha menoleh kembali kepada orang yang membagikan nasi tadi ternyata sudah tidak ada. Rupanya orang tersebut sudah lama melarikan diri. Ternyata orang itu penghianat dimana para pejuang diberi umpan nasi (Pindha, 1968a).

Di daerah Kintamani cara Belanda (NICA) menarik hati rakyat dengan membagi - bagikan jajan, rokok, dan uang logam dengan cara dihamburkan. Dalam hal ini rakyat menganggap Belanda sangat dermawan. Selain itu Belanda (NICA) berjanji akan lekas kembali membawa kain batik dan uang logam sebanyak - banyaknya. Demikianlah tindakan Belanda mempengaruhi rakyat (Pindha, 1968a). Begitu pula dengan I Gusti Ngurah Munang Wirawan dimasa kecil di desanya Taman Punggul, Blahkiuh Badung sempat menjadi tawanan NICA. I Gusti Ngurah Munang Wirawan pada waktu itu sengaja dirayu penguasa (NICA) agar mau membeberkan persembunyian ayahnya yang dijuluki Pak Sugriwa. I Gusti Ngurah Munang Wirawan diperlakukan sangat simpatik oleh seorang Mayor Belanda dengan memberikan roti, pakaian serta mengajak jalan jalan naik mobil dengan harapan dapat mengorek berbagai keterangan. Untung sang bibi yang menemaninya berhasil mencegahnya, meskipun sempat dibentak oleh penguasa (NICA) yang dibantu oleh AP. Pancingan NICA yang menjadikannya I Gusti Ngurah Munang Wirawan sebagai tameng di atas mobil, akhirnya gagal memancing keluar ayahnya dari tempat persembunyian ("Mantan Tawanan Kecil, Munang Yang Kadis LLAJ Bangli," 1991).

Di daerah Pengajaran Belanda (NICA) mengerahkan rakyat untuk membantu pengurungan pemuda. Rakyat mau turut mengejar pemuda karena beberapa alasan. Ada yang karena takut, ada yang mengira pemuda itu adalah pengacau, perampok atau penggarong seperti yang diprovokasikan oleh Belanda (NICA). Demikian Ngurah Raka pemuda yang kesasar terpisah dengan pasukan induk. Baru saja beberapa puluh meter dapat menjauhi tepi jurang, tiba - tiba "Ih jero, ragane pemuda" (He saudara, apakah saudara pemuda). Ngurah Raka dihadapannya melihat seorang yang berbadan besar, kuat dan memegang sebuah parang besar memandangnya dengan tajam. "Nggih tiang pemuda, sapunapi" (Ya saya pemuda, kenapa). "Yan pemuda, lakar juk" (Kalau pemuda, mau saya tangkap). "Inggih rarisang ejuk sampun" (Ya silahkan tangkap saya) jawab Ngurah Raka. Ngurah Raka sendiri tidak bersenjata. Merlihat ketenangan Ngurah Raka dan selalu, menjawab dengan bahasa daerah yang halus. Melihat rupa pemuda orang baik - baik tidak mirip perampok atau pembunuh seperti apa yang dikatakan oleh Belanda. Selanjutnya orang itu bertanya agak lain. "Mangkin dumun, tiang metaken ragane pemuda saking dija" (Tunggu dulu, saya mau bertanya saudara pemuda dari mana). "Tiang saking Gerana" (Saya dari Gerana). Orang itu selanjutnya maju mendekati serta berkata dengan berbisik " mohon ampun beribu- ribu ampun atas kesalahan saya". Sekarang jangan berjalan terus, tidak jauh dari sini banyak serdadu Belanda. Mari ikuti saya, orang itu berjalan lebih dulu dan diikuti oleh Ngurah Raka menuju ke jurang lagi. Setelah sampai dibawah kembali diajak menuju ke sebuah gua. Nah tuan (Ngurah Raka) bersembunyilah disini sampai 
Vol. 2, No. 1, Januari 2018, 14

Available Online at https://ejournal.warmadewa.ac.id/index.php/kulturistik DOI: dx.doi.org/10.22225/kulturistik.2.1.442

serdadu Belanda (NICA) itu pergi dari daerah ini. Saya akan sewaktu - waktu datang kemari pada malam hari kata orang itu. Ngurah Raka tinggal di dalam gua itu selama 3 hari 3 malam (Pindha, 1968b).

Salah seorang pejuang yang ditangkap oleh NICA yaitu I Dersana. Masyarakat dipanggil berkumpul oleh NICA dengan tujuan untuk melihat atau menyaksikan I Dersana ditembak dimuka umum. Setelah menembak I Dersana di muka umum, Belanda (NICA) pergi begitu saja. Adapun tujuannya supaya masyarakat merasa takut dan jera membantu para pejuang. Setelah Belanda (NICA) pergi jauh I Dersana selanjutnya bangun kembali ternyata tidak mati meskipun dadanya kena peluru dendem (Simpen AB, 1984).

Setelah pasukan I Gusti Ngurah Rai berhasil menyerobot tangsi NICA di Tabanan, akhirnya selama tujuh hari M. Wagimin ditahan dan disiksa secara kejam oleh kompeni. Wagimin sama sekali tidak mau membuka rahasia gerakan perjuangan meskipun Wagimin diarak keliling kota Tabanan. Sambil didirikan di tiang bendera di tangsi polisi Tabanan, M Wagimin ditanya oleh Detasement Comandant Polisi Tabanan, apakah Wagimin masih setia kepada republik. Pertanyaan itu dijawab dengan suara lantang dan berani, bahwa Wagimin sudah bosan melihat muka Belanda dan menyatakan memilih mati sambil meludah kemuka tuan Rammel Zwals dan mengeluarkan kata - kata "kamu adalah anjing - anjingnya Belanda". M.Wagimin dikonfrontasikan dengan semua anggota polisi yang ikut menyerahkan senjatanya. Dengan tegas Wagimin menyatakan mereka itu semua itu tidak tahu apa - apa dan mereka hanya menjalankan perintahnya saja. Belanda tidak berhasil mengorek keterangan dari M. Wagimin dengan alasan untuk diobati M. Wagimin diajak ke lokasi pertempuran di Margarana dan sesampainya disana Wagimin ditrewmbak mati oleh kompeni secara kejam (Lastra, 1984: VII).

Propokasi musuh (Belanda/NICA) yang disampaikan melalui kaki tangannya yaitu menyatakan bahwa seluruh pemuda anak buah Ngurah Rai sudah hancur dibom dan ditembak. Berita - berita demikian sering disebarkan dan kadang kadang disertai dengan beberapa mayat pemuda yang sengaja dipertunjukkan untuk meruntuhkan semangat rakyat berjuang. Kadang - kadang kaki tangannya sendiri (HP, NICA Gandek, serdadu sewaan) yang mampus digempur pemuda pemuda kita, mereka telanjangi dan dipertontonkan secara licik supaya sukar diingat, dan dikatakan bahwa mayat - mayat itu adalah bangkai pemuda. Demikian $\mathrm{ibu}$ - ibu dan kaum priya yang kurang mengerti akan termakan propokasi sehingga digoncang jiwanya. Kita kagum akan kepandaian NICA membuat propokasi. Akal demikian sering kali digunakan untuk sementara berhasil juga (Pindha, 1964). A.A. Putra dengan nama samaran "Maruti" ketika berkunjung ke desa Ringdikit, sebelah selatan Bubunan, ia dan beberapa pemuda pejuang lainnya kena kurungan militer Belanda (NICA). Desa dikepung dari segala penjuru, hingga pemuda - pemuda pejuang dalam keadaan terjepit. Dengan senjata pistol di tangannya, Maruti mengadakan perlawanan sengit. Berhubung tentara Belanda yang dihadapi bersenjata lengkap dan modern dalam tembak menembak di sungai di sebelah barat desa, Maruti akhirnya gugur bersama seorang temannya bernama Sumpena. Jenasahnya dibawa oleh serdadu - serdadu NICA ke Seririt, kemudian dipertontonkan dan diseret untuk menakut - nakuti rakyat. Pada akhirnya, jenasah A.A. Putra dimakamkan oleh masyarakat desa Bubunan di kuburan desa tersebut ("Mengenang Gugurnya Pahlawan Maruti," 1986). Pada waktu terjadi revolusi fisik, Made Anila tidak tinggal diam melawan Belanda. Ia ingat akan sumpahnya 
Vol. 2, No. 1, Januari 2018, 15

Available Online at https://ejournal.warmadewa.ac.id/index.php/kulturistik DOI: dx.doi.org/10.22225/kulturistik.2.1.442

yang dilontarkan di depan Letnan Damme yang bule itu. "Kalau kelak bangsaku berhadapan melawan bangsamu, aku tidak akan menyerah setapakpun". Ia menambahkan "Aku rela berkorban untuk bangsaku". Setelah itu mereka berpisah, Letnan Damme bersama - sama perwira-perwira Belanda lainnya menuju Gilimanuk, sedangkan Made Anila bersama - sama rekan - rekannya menyusup ke hutan - hutan kawasan Gunung Batukaru. Dari sini Made Anila menuju desanya yakni Bestala di kecamatan Seririt. Pada suatu hari, ketika udara cerah satu regu pasukan Belanda datang melakukan patroli ke desa Bestala. Setelah mendengar informasi NICA datang, Made Anila segera mengambil posisi. Kebetulan rumah tempat tinggal Made Anila posisinya lebih di atas dari pasukan Belanda yang sudah mulai mendekat, sebelum keluar rumah Made Anila berkata kepada istrinya "Granat - granat inilah yang akan menentukan nasibku". Made Anila segera menuju ke sebuah kebun yang ada di sebelah rumahnya. Made Anila bersembunyi di balik pohon nyiur, sementara pasukan NICA sudah sangat dekat. Setelah jarak ditentukan, Made Anila melempar sebuah granat tetapi macet tidak mau meledak. Made Anila kembali mengambil sebuah granat lagi dari dalam sakunya, ketika hendak dilemparkan granat itu meledak ditangannya. Pada waktu itu peluru stein NICA lebih dulu menembus dada Made Anila. Peristiwa itu terjadi tanggal 4 April 1946, jasad Made Anila keadaannya hancur, kemudian diseret oleh NICA tanpa prikemanusiaan. Teman - teman Made Anila seperjuangan yang menyaksikan peristiwa ini dari kejauhan berlarian tungganglanggang cerai- berai ("Made Anila Bersumpah Tak Akan Menyerah," 1988).

Bermula dari seorang tentara Belanda secara iseng membuka laci meja tulis Md Tirta yang terletak dikamar tamunya. Ternyata ditemukan sebuah granat tangan dan sehelai pita merah putih pengikat kepala. Dipegangnya lengan Md Tirta, selanjutnya ditarik turun kehalaman untuk mulai diinterogasi. Dengan sengitnya Belanda melakukan interogasi terhadap Md Tirta. Mata - mata Belanda bertanya dari mana mendapatkan granat itu dan siapa pemiliknya. Md Tirta menerangkan dengan sebenarnya bahwa granat itu milik orang Cina dari Perean. Md Tirta mengenal orang Cina itu dari dahulu dan menyuruh menyimpan dirumahnya. Pertanyaan yang diajukan Belanda tidak memuaskan, selanjutnya Md Tirta digiring dan ditempatkan di kosentrasi kamp Tulangampiang. Sudah jelas dapat diduga orang Cina itu tidak akan mengaku. Dapat dibayangkan nasib apa yang menanti Md Tirta. Semua alat - alat penyiksaan berturut - turut dihantamkan kebadan Md Tirta. Tidak memilih tempat, dari kaki sampai ke muka, popor senapan dari 4 orang tentara Belanda silih berganti dihantamkan kebadan Md Tirta sekuat tenaga. Entah berapa kali Md Tirta tidak sadarkan diri, bermandikan darah sekujur tubuhnya. Dalam keadaan sekarat Md Tirta dipindahkan lagi ke kamp Beha dimana disiksa tanpa batas dan tidak berkesudahan selama 18 hari. Sekitar jam 10.30 datanglah Johan dan Ing ke rumah Md Tirta di Tegallinggah diikuti beberapa orang dibelakangnya memikul jenasah yang dijaga beberapa tentara Belanda. Meme, ini mayat anakmu, ia sudah mati. Kata Johan sambil melemparkan senyumnya mengejek. Selanjutnya ibu Md Tirta mendekati jenasah itu, dibukanya perlahan - lahan penutupnya dan alangkah terkejutnya. 18 hari yang lalu anak saya meningggalkan rumah ini masih dalam keadaan utuh. Mengapa kamu kembalikan ia tidak berkulit lagi. Ya, itu salahnya sendiri, kata Johan dengan nada dingin. Sedangkan semua pengawal sudah mengacungkan laras senapannya kearah keluarga Md Tirta. Md Tirta kami tinggalkan sendiri dibelakang jeep sambung Johan tiba - tiba meloncat turun mau lari. Berhubung 
Vol. 2, No. 1, Januari 2018, 16

Available Online at https://ejournal.warmadewa.ac.id/index.php/kulturistik

DOI: dx.doi.org/10.22225/kulturistik.2.1.442

tali pengikatnya masih tersangkut dibelakang jeep, tentulah Md Tirta terseret terus sepanjang jalan tanpa kami ketahui dari Beha sampai kota Denpasar. Kondisi mayat Md Tirta dalam keadaan hancur, kedua lengan dan punggungnya patah, badan penuh bengkak - bengkak lama dan baru, kemaluan hancur, mata tidak dapat melihat, sebuah lengan dan pinggangnya diikat. Tanpa ada ucapan bela sungkawa lagi, rombongan Johan mengundurkan diri meninggalkan keluarga $\mathrm{Md}$ Tirta yang sedang dalam suasana sedih (Wijakusuma., 1979: IV)

Di Desa Bingin Bebetin disalah satu bukit tertinggi pasukan pejuang segera mengatur pengawalan dan mempelajari keadaan medan sambil memperkenalkan diri kepada masyarakat karena memang masyarakat disana sepenuhnya membantu gerilyawan. Keadaan medannya sangat menguntungkan untuk melancarkan serangan mendadak dan pencegatan terhadap patroli NICA karena penuh dengan bukit - bukit. Di daerah ini sering pemuda - pemuda kita mengadakan cegatan cegatan terhadap NICA beserta AP-nya (Anti Pemuda). Dari hari ke hari cegatan - cegatan selalu dilakukan sehingga NICA merasa kewalahan, dan mereka memperbesar pasukan patrolinya dengan persenjataan serba modern. Padi yang menguning di sawah dan di lumbung dibakar habis oleh NICA untuk melemahkan persediaan makanan pejuang. Namun pejuang tidak pernah merasa kekurangan makanan berkat bantuan seluruh rakyat Bebetin dan sekitarnya. Malam harinya para pejuang juga mengadakan serangan balasan kepada desa yang membantu NICA dan menembaki mata - mata NICA (Suwela, 1979: V).

Peristiwa tertangkapnya pemuda Widnya menyebabkan rakyat Bondalem sangat tersinggung, lalu segera mengadakan mobilisasi serta mengatur taktik strategi perjuangan. Beberapa hari berselang, datang pasukan AP ke desa Bondalem lalu memasuki setiap rumah. Pasukan AP tidak berhasil menemukan pemuda, selanjutnya barang - barang dan perhiasan rumah tangga menjadi sasaran. Termasuk barang - barang milik Hartawan Mataram. Para penggarong sempat menaruh sepucuk surat yang nadanya menantang. Sudah tentu rakyat dan pemuda Bondalem makin benci dan perasaan pantang mundur ingin melakukan pembalasan. Mereka semua bersumpah di Pura Dalem kalau musuh datang lagi akan melawan habis - habisan ("28 Pemuda Gugur Sebagai Bunga Di Bon Dalem," 1985).

Pada tanggal 8 April 1946, dalam suatu rapat pimpinan berbicaralah Ida Bagus Putu Djapa dimana ingin menggempur kota Denpasar yang telah dikuasai NICA. Ida Bagus Putu Djapa tidak tega melihat pemuda lainnya disiksa oleh NICA seperti disuruh menelan lencana merah putih yang terbuat dari seng. Dalam rapat tersebut ada yang mengusulkan agar terlebih dahulu menyerang pos - pos serdadu NICA kecil yang ada di desa - desa. Dengan tegas Ida Bagus Putu Djapa berkata kami tidak setuju serangan kecil - kecilan kita harus menyerang kota. Akhirnya Kapten Sugianyar dalam rapat pimpinan yang memiliki pangkat tertinggi menengahi dan memutuskan bahwa kota akan diserang. Berhasil atau tidak yang penting telah menunjukkan kekuatan serta telah memenuhi keinginan pemuda di kota ("Kapten Ida Bagus Putu Djapa Pejuang Kemerdekaan Dari Bali," 1990).

Pada bulan Mei 1946 setelah beberapa hari MBUDPRI bermukim di desa Bengkelanyar yang aman dan tenteram, kedudukan markas pejuang di kaki Gunung Batukaru ini akhirnya diketahui oleh tentara NICA. Terbukti setiap hari kapal capung penyelidik Belanda terus menerus melakukan pemantauan di atas udara desa ini dan sekitarnya. Kadang - kadang kapal capung ini melemparkan 
granat dari udara untuk ditujukan kepada orang - orang yang dilihatnya bergerombol bahkan terhadap para wanita yang sedang mengetam padi (Tirtayasa, 1992: 8).

\section{SIMPULAN}

Revolusi fisik yang terjadi di Bali dari tahun 1945 - 1950 cukup lama dapat dipertahankan oleh para pejuang dalam menghadapi Belanda. Hal ini disebabkan karena pejuang dengan rakyat pada waktu itu bersatu. Berbagai macam taktik atau strategi dilakukan oleh para pejuang sehingga Belanda sangat sulit untuk mengalahkannya. Pada waktu itu Belanda sudah menggunakan peralatan tempur yang jauh lebih modern dari para pejuang. Dalam menghadapi para pejuang di Bali selain menggunakan kekuatan militer, Belanda juga menggunakan tindakan lain untuk mempengaruhi rakyat seperti: membagikan jajan, rokok, uang logam, kain batik, dan nasi. Tindakan yang dilakukan oleh Belanda kepada rakyat baik secara langsung maupun tidak langsung melalui mata matanya. Tujuan melakukan tindakan ini agar rakyat bersimpati kepada Belanda. Berhubung tindakan ini tidak mampu mempengaruhi rakyat, Belanda juga melakukan tindakan kekerasan. Tindakan tersebut seperti: pejuang yang tertangkap disuruh menelan lencana merah putih, menggeranat dari udara dengan pesawat capung melihat orang bergerombol termasuk para wanita yang sedang mengetam padi di sawah, diarak di depan umum yang selanjutnya pejuang tersebut ditembak dan diseret dengan mobil. Selain itu Belanda juga membakar padi di sawah - sawah serta lumbung - lumbung padi milik penduduk. Tindakan Belanda tersebut di atas bertujuan untuk melemahkan perjuangan rakyat di Bali. Namun demikian para pejuang tidak mengenal lelah mereka bahu - membahu bersama sama rakyat untuk mengusir Belanda dari muka bumi pulau Bali.

\section{DAFTAR PUSTAKA}

28 Pemuda Gugur Sebagai Bunga Di Bon Dalem. (1985, September 22). Bali Post. Denpasar.

A. Giri, W. D. (1984). Lintasan peristiwa puputan margarana. Denpasar: YKP Daerah Propinsi Bali.

Hardjawiganda, R., \& dkk. (1982). Operasi lintas laut Banyuwangi-Bangli. Jakarta: Departemen Pertahanan Keamanan Pusat Sejarah ABRI.

Jajasan Kebaktian Proklamasi Daerah Propinsi Bali. (1968). Sedjarah singkat pahlawan nasional Kolonel Anumerta I Gusti Ngurah Rai. Marga.

Jarahdam XVI Udayana. (1974). Monumen perjuangan kemerdekaan Di Bali. Denpasar.

Kapten Ida Bagus Putu Djapa Pejuang Kemerdekaan Dari Bali. (1990). Bali Post. Denpasar.

Kartodirdjo, S., \& dkk. (1977). Sejarah Nasional Indonesia VI. Jakarta: PN Balai Pustaka.

Lastra. (1984). Wagimin ditembak mati, setelah seminggu ditahan dan disiksa. Denpasar: Bali Post.

Made Anila Bersumpah Tak Akan Menyerah. (1988). Bali Post. Denpasar.

Mantan Tawanan Kecil, Munang Yang Kadis LLAJ Bangli. (1991). Bali Post. Denpasar.

Mengenang Gugurnya Pahlawan Maruti. (1986). Bali Post. Denpasar.

Pendit, N. S. (1979). Bali Berjuang. Jakarta: Gunung Agung. 


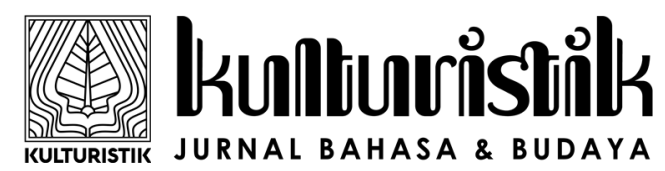

Vol. 2, No. 1, Januari 2018, 18

Available Online at https://ejournal.warmadewa.ac.id/index.php/kulturistik

DOI: dx.doi.org/10.22225/kulturistik.2.1.442

Pindha, I. G. N. (n.d.). "Gempilan perjuanganphysik di Bali, Men Bolong memanggil dalam gempilan Perjuangan Physik Di Bali."

Pindha, I. G. N. (1964). Men Bolong Memanggil. Harian Pagi Suara Indonesia. Denpasar.

Pindha, I. G. N. (1968a). Gempilan Perjuangan Physik Di Bali, Masa - Masa Krisis X. Harian Pagi Suluh Marhaen. Denpasar.

Pindha, I. G. N. (1968b). Gempilan Perjuangan Physik Di Bali, Masa - Masa Krisis XXIII. Harian Pagi Suluh Marhaen. Denpasar.

Simpen AB, I. W. (1984). Pengalaman Hidup. Bali Post. Denpasar.

Suralaga, I. (1982). Puputan Margarana. Denpasar: Bali Post.

Suwela, M. (1979). Suatu pagi di Desa Bingin Bebetin. Denpasar: Bali Post.

Tirtayasa, I. M. (1992). Pengalaman Perjuangan mengikuti perjalanan gerilya Letkol I Gusti Ngurah Rai (6). Denpasar: Bali Post.

Wijakusuma. (1979). Kisah perdjuangan gerilya di Bali (II), pulang tanpa kulit. Bali Post. Denpasar. 